\title{
SURFACE-TREATED AND FIBRIN-COATED ELECTROSPUN POLYACRYLONITRILE FIBER FOR ENDOTHELIAL CELL GROWTH AND PROLIFERATION
}

\author{
UDC 678.754.3:678.026
}

\section{Nur Syazana Rashidi ${ }^{1}$, Irza Sukmana ${ }^{2}$, Agung Mataram ${ }^{3}$, Noor Jasmawati ${ }^{1}$, Mohd Ramdan Mohd Rofi ${ }^{1}$, Mohammed Rafiq Abdul Kadir ${ }^{1}$}

\author{
${ }^{1}$ Medical Devices and Technology Group (MEDITEG), \\ Faculty of Bioscience and Medical Engineering, Universiti Teknologi, Malaysia \\ ${ }^{2}$ Faculty of Engineering, Universitas Lampung, Indonesia \\ ${ }^{3}$ Faculty of Engineering, University of Sriwijaya, Indonesia
}

\begin{abstract}
Polyacrylonitrile (PAN) is a synthetic biocompatible polymer used as a filtering membrane in hemodialysis and for enzyme immobilization purposes. However, its potential usage in other medical applications is limited due to its poor hydrophilicity. To overcome this problem, two groups of electrospun PAN fibers were treated with sodium carbonate $\left(\mathrm{Na}_{2} \mathrm{CO}_{3}\right)$ and sodium hydroxide $(\mathrm{NaOH})$, respectively at $100^{\circ} \mathrm{C}$ for 5 minutes. Fibrin gel was then coated onto the treated samples before seeding human umbilical vein endothelial cells (HUVECs) for 1 and 3 days. X-ray diffraction results showed increased crystallinity of the PAN fibers when treated with $\mathrm{Na}_{2} \mathrm{CO}_{3}$ and $\mathrm{NaOH}$. The contact angle measurements showed that the hydrophilicity of $\mathrm{Na}_{2} \mathrm{CO}_{3}$ treated and $\mathrm{NaOH}$ treated samples improved from $115^{\circ}$ to $88^{\circ}$ and $64^{\circ}$, respectively. The Fourier transform infrared spectroscopy confirmed that their hydrophilicity was due to the existence of carboxyl and hydroxyl groups. However, tensile strength of the PAN fibers was reduced by $34 \%$ when treated with $\mathrm{Na}_{2} \mathrm{CO}_{3}$ and $42 \%$ when treated with $\mathrm{NaOH}$. Cytotoxicity tests showed increased absorbance in day 3 for both treated samples. However, the absorbance value for $\mathrm{NaOH}$ treated PAN fibers and $\mathrm{Na}_{2} \mathrm{CO}_{3}$ treated PAN fibers showed nearly the same absorbance on day 7. In vitro tests showed increased cell adhesion and proliferation after 3 days of culture. The PAN treated fibers coated with fibrin are, therefore, proven to attract HUVEC cells and promote endothelialization.
\end{abstract}

Key Words: Polyacrylonitrile Fibre, Surface Treatment, Scaffold, Endothelial Cells

\footnotetext{
Received September 13, 2017 / Accepted October 25, 2018

Corresponding author: Irza Sukmana

Department of Mechanical Engineering, Faculty of Engineering, Universitas Lampung, Jl. Prof. Soemantri Brojonegoro No. 1, Bandar Lampung 35145, Indonesia

E-mail: irza.sukmana@eng.unila.ac.id

Cㅇ 2018 by University of Niš, Serbia| Creative Commons License: CC BY-NC-ND
} 


\section{INTRODUCTION}

Due to its high biomechanical strength, thermal stability, tolerance to solvents as well as its resistance to bacteria and photo irradiation effects, Polyacrylonitrile (PAN) has been used extensively to produce various manufactured materials [1]. These include products such as commercial carbon fibers, filtration [2], adsorption [3], as well as weaved products such as blankets, carpets and clothes [4]. PAN is also proven as a biocompatible material suitable for biomedical purposes such as tissue-engineered bioartificial skin [5], hemodialysis [6], and biocatalysts immobilization [7].

However, due to its poor hydrophilicity, the use of PAN without surface treatment appears limited. Therefore, the surface treatments used for overcoming this problem have been described in the referential literature. They include methods such as plasma treatment [8-10], plasma initiated graft polymerization [11,12], and photoinduced grafting [13]. Yet, these methods have inherent limitations. Compounded by the high cost involved in the treatment process, many of them have been deemed impractical for large scale manufacturing purposes [14]. It has been suggested that the use of $\mathrm{Na}_{2} \mathrm{CO}_{3}$ and $\mathrm{NaOH}$ solutions in Millipore-purified water can be used to provide similar effects without involving exorbitant cost $[15,16]$.

The promotion of endothelial adhesion and vascularization to prevent thrombosis as well as intimal hyperlasia of a small diameter vascular graft has been tested to the PAN fibers. Previous studies have shown that without the fibrin coating process, the cell differentiation onto the material surfaces would be non-existent thus rendering the material less useful for vascularization of an engineered-tissue substitute [17]. The role of fibrin actively directs cellular responses through specific receptor-mediated interactions with endothelial cells of the vessel wall [18]. Therefore, the use of fibrin as a coating active matrix onto a bioactive scaffold to support endothelialization is of interest. However, no study has been done yet to show that the electrospun PAN fibers with $\mathrm{Na}_{2} \mathrm{CO}_{3}$ and $\mathrm{NaOH}$ surface treatment followed by fibrin coating can form endothelial cells monolayer for blood vessel.

The surface treatment using $\mathrm{NaOH}$ is nevertheless already established for PAN materials by authors mostly in ultrafitration and hemodylisis applications [19, 20]. However, the effects of $\mathrm{Na}_{2} \mathrm{CO}_{3}$ treatment on the PAN mechanical and physical properties have not been intensively studied compared with $\mathrm{NaOH}$ surface treatment. Research on $\mathrm{Na}_{2} \mathrm{CO}_{3}$ surface treatment onto PAN only covered a hydrolysis part while biocompatibility has not been addressed before $[15,20]$. The present study aims at analyzing hydrophilicity of the treated PAN fibers with $\mathrm{Na}_{2} \mathrm{CO}_{3}$ and $\mathrm{NaOH}$. The PAN treated surfaces are then coated with fibrin gel to provide covalently attached bioactive compound. Therefore, the present study needs more cell attachment for the future tissue engineering; also, it has managed to develop a new technique utilizing fibrin gel coating on the treated PAN fiber. This study also determines a change in biophysical surface appearance, surface chemistry and biomechanical properties, as well as bioactivity and biocompatibility of the PAN fibers before and after undergoing surface treatment followed by fibrin coating. 


\section{MATERIALS AND METHODS}

\subsection{Materials}

Polyacrylonitrile (PAN; Mw=150,000; $53.06 \mathrm{~g} / \mathrm{mol}$ ), N,N-dimethylformamide (DMF; $73.10 \mathrm{~g} / \mathrm{mol}$ ) and acrylamide (AM; 71.08g/mol) were bought from Aldrich Chemical and were used without further purification. Other materials are Sodium hydroxide $(\mathrm{NaOH}$; Sigma Aldrich, USA), Sodium carbonate $\left(\mathrm{Na}_{2} \mathrm{CO}_{3}\right.$; Sigma Aldrich; USA), Fibrinogen and Thrombin (Sigma Aldrich; USA). Human umbilical vein endothelial cells (HUVEC) were purchased from Promo-Cell (C-12200, Heidelberg, Germany).

\subsection{PAN fiber preparation}

The random PAN fibers were developed through electrospinning under optimum conditions. Briefly, $14 \%$ (w/v) of PAN was dissolved in a DMF solution. This solution was loaded into a $5 \mathrm{~mL}$ glass syringe and the flow rate of $2 \mathrm{~mL}^{-1} \mathrm{~h}^{-1}$ was controlled by the syringe pump. A high voltage $(21 \mathrm{kV})$ was applied using a high voltage regulated DC power supply (Model ES 30P-5W, Gamma High Voltage Research, Ormond Beach, FL). A piece of aluminum foil was placed towards the tip at the distance of $12 \mathrm{~cm}$ as grounded collector. Afterwards, the electrospun fibers were peeled off from the aluminum foil and the residual solvent was released in an oven at $40^{\circ} \mathrm{C}$. The dried electrospun fibers were then stored in the desiccator prior to further processes.

The electrospun PAN fibers mat was cut by $2 \mathrm{~cm} \times 2 \mathrm{~cm}$. One percent w/v aqueous solution of $\mathrm{Na}_{2} \mathrm{CO}_{3}$ was prepared. The PAN fiber was dropped into boiling $\mathrm{Na}_{2} \mathrm{CO}_{3}$ at temperature $100^{\circ} \mathrm{C}$ for 5 minutes and then it was rinsed with plenty of water until $\mathrm{pH} \sim 7$. The substrate then was dried at ambient temperature $\left(\mathrm{T} \sim 25^{\circ} \mathrm{C}\right)$ for 24 hours. This step was repeated for $\mathrm{NaOH}$ surface treatment. The PAN fiber was sterilized by immersing it in $10 \%$ penicillin-streptomycin under ultraviolet light (UV) for 15 minutes. Next, the substrate was dried under UV for 1 hour.

In 24 well plates, fibrin gels were prepared using $500 \mu \mathrm{l} /$ well of fibrinogen solution $(2.0$ mg.mL $L^{-1}$ ) made in phosphate buffered saline (PBS). This solution was directly mixed with $1 \mathrm{mg} /$ $500 \mu \mathrm{l}\left(100 \mathrm{U}_{\mathrm{mL}}^{-1}\right.$ in PBS) for polymerization process of fibrinogen into fibrin. The PAN fiber after $\mathrm{Na}_{2} \mathrm{CO}_{3}$ and $\mathrm{NaOH}$ treatment was transferred and deposited in the prepared fibrin gel. The fibrin-coated PAN fiber was then stored in an incubator at $4^{\circ} \mathrm{C}$ overnight. Afterwards, the substrate was dried on the filter paper at room temperature in sterile conditions.

\subsection{Surface characterization}

The morphology of the fabricated scaffolds before and after the surface treatment and the coated PAN fibers were observed by a high-resolution field emission scanning electron microscope (FESEM; ZEISS Supra 35VP), operated at an acceleration voltage of $10 \mathrm{kV}$. The fibers diameters were measured by the SEM (JEOL, JSM-6390LV) micrographs measured randomly within an average of 50 fibers. The PAN fiber composition before and after the surface treatment and coating was determined by the Energy Dispersive X-ray spectroscopy (EDS).

The Fourier transformed infrared (FTIR) spectra of the fibers were collected on the Perkin-Elmer Spectrum 2000 in order to analyze the chemical structure of the electrospun PAN fiber over a range of $400-4000 \mathrm{~cm}^{-1}$ with typically 32 scans at a resolution of $4 \mathrm{~cm}^{-1}$. 
Also, the crystallinity of the sample was characterized by x-ray diffraction (XRD) (D5000, Siemens, Germany) in a thin film mode at $40 \mathrm{kV}$ and $40 \mathrm{~mA}$. The data were recorded in $2 \theta$ range using $\mathrm{CuK} \alpha$ radiation of $1.5406 \AA$.

The water contact angle of the PAN fibers before and after the surface treatment were measured using VCA Optima (AST Product, Inc.) mounted with a CCD camera. The fiber was placed on the sample stage and a drop of ultrapure water (Milli-Q, $2 \mu \mathrm{L}$ ) was dropped to the surface for contact angle measurement. Five points per fiber were measured to determine the mean value of the water contact angle $(n=3)$.

\subsection{Mechanical properties}

The samples were cut using a punch die ( $3 \mathrm{~mm}$ wide and $3 \mathrm{~cm}$ length) and tested using a tensile machine (Instron 8845) with a load cell capacity of $10 \mathrm{kN}$. The appropriate specimen gripping as shown in Fig.1 (i) is required to prevent the fibers from breaking or slipping at the grips. According to ASTM D882, the samples were mounted and had a 25 $\mathrm{mm}$ gage length. The samples were prepared for testing at a crosshead speed of $5 \mathrm{~mm} / \mathrm{min}$ at ambient conditions. The initial modulus, ultimate strength and elongation at ultimate strength were measured.

\subsection{Endothelial cell responses}

Human umbilical vein endothelial cells (HUVECs) were cultured in endothelial cell growth (Promo Cell) supplemented by 1\% antibiotic penicillin-streptomycin (Gibco, USA). The cells were replaced twice a week and cultures were maintained at $37^{\circ} \mathrm{C}$ in the incubator containing $5 \% \mathrm{CO}_{2}$. HUVEC between passages 3 and 5 were used in all experiments. After coating process, the sterile fibrin-coated PAN fibers treated with $\mathrm{Na}_{2} \mathrm{CO}_{3}$ and $\mathrm{NaOH}$ were seeded with HUVECs at a density of $3 \times 10^{4}$ cells/ $/ \mathrm{cm}^{2}$ in 24 well-plates and observed for day 1 and day 3 .

Cell morphology was studied using the Axio Vert A1 inverted microscope and the SEM (Carl Zeiss). The substrates were fixed in $2 \%$ glutaraldehyde ( $0.1 \mathrm{M}$ phosphate buffered) for $2 \mathrm{~h}$ and then washed with ethanol series before being observed under the SEM. For staining procedure, HUVEC-seeded-on-fibers were gently washed with PBS (3 times) and fixed with formaldehyde solution $(3.75 \% \mathrm{wt} / \mathrm{v})$ in PBS for $20 \mathrm{~min}$. The sample was then washed three times with PBS and then permeabilized with a Triton X-100 solution ( $0.5 \% \mathrm{v} / \mathrm{v}$ in PBS) for 15 minutes. The sample was finally rinsed three times in PBS and stained with Hoechst 33258 (1:10,000 dilution, catalog \#B2883; Sigma Aldrich) for 1 hour at room temperature and in dark. To assess the intracellular of HUVECs, the sample then was washed with PBS three times before being stained with Alexa Fluor 488, Life technologies for 1 hour. Finally, after washing with PBS, the sample was conserved with $3 \mathrm{~mL}$ per well of PBS and observed under microscope. The MTT assay was used as a measure of relative cell viability. HUVECs were harvested and seeded onto the samples at $1 \times 10^{4} \mathrm{cells} / \mathrm{cm}^{2}$ for a specified time of $1,3,5$ and 7 days in 96-well plate with endothelial cell specific medium changes every 2 days. The cell viability was evaluated using the MTT assay (MTT; Sigma), in which $100 \mathrm{ml}$ of MTT $(5 \mathrm{mg} / \mathrm{ml})$ was added to each well and incubated at $37^{\circ} \mathrm{C}$ for $4 \mathrm{~h}$. At the end of the assay, the blue formazan reaction product was dissolved by adding DMSO. The absorbance was measured at $570 \mathrm{~nm}$ using a microplate reader (Thermo scientific; US). 


\section{RESULTS}

\subsection{Morphology of untreated and treated PAN fiber}

FESEM images of the electrospun PAN fibers are to investigate the effect of the surface treatment upon the fiber morphology structure presented in Fig. 1.
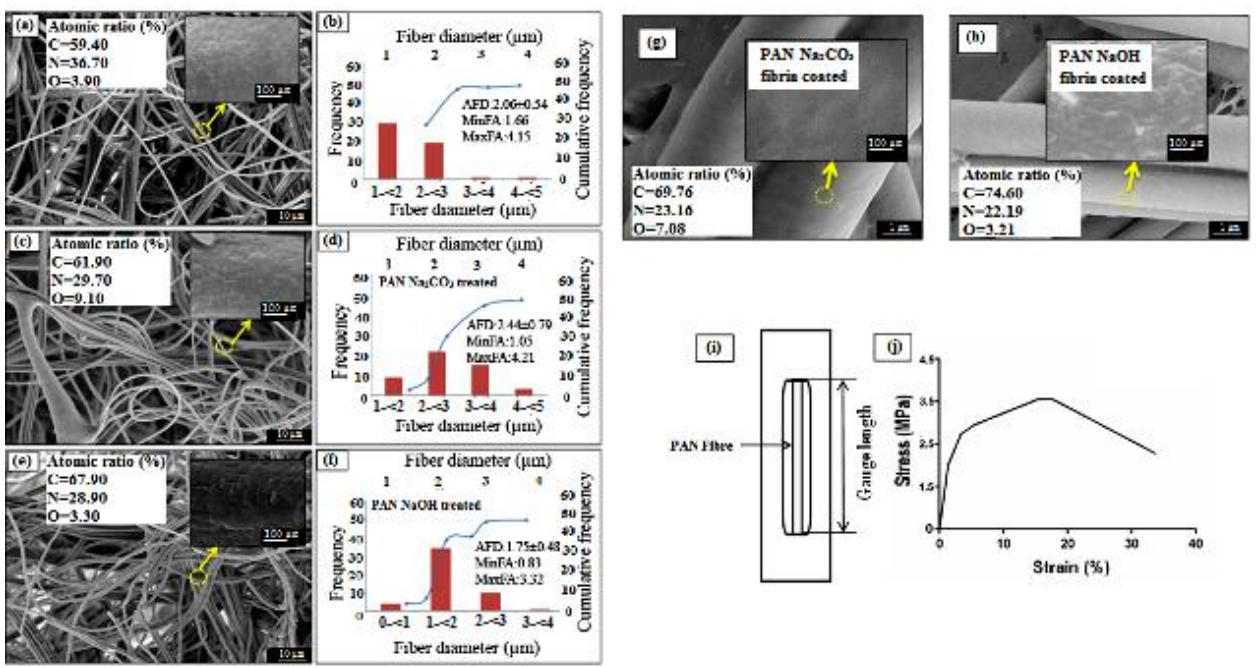

Fig. 1 FESEM micrograph and distribution of untreated PAN fiber $(a, b)$; fiber treated with $\mathrm{Na}_{2} \mathrm{CO}_{3}(\mathrm{c}, \mathrm{d})$ as well as with $\mathrm{NaOH}(\mathrm{e}, \mathrm{f}) . \mathrm{Na} 2 \mathrm{CO} 3(\mathrm{~g})$ and $\mathrm{NaOH}$

(h) treated fiber then coated with fibrin, (i) mounting tab for tensile test (j) stress strain curve PAN control

Table 1 Mechanical properties of PAN before surface treatment and PAN after surface treatment with $\mathrm{Na}_{2} \mathrm{CO}_{3}$ and $\mathrm{NaOH}$

\begin{tabular}{lccc}
\hline $\begin{array}{l}\text { Mechanical } \\
\text { Properties }\end{array}$ & $\begin{array}{c}\text { PAN before } \\
\text { surface treatment }\end{array}$ & $\begin{array}{c}\text { PAN - surface treatment } \\
\text { with } \mathrm{Na}_{2} \mathrm{CO}_{3}\end{array}$ & $\begin{array}{c}\text { PAN - surface treatment } \\
\text { with } \mathrm{NaOH}\end{array}$ \\
\hline Tensile strength (MPa) & $3.77 \pm 0.68$ & $2.46 \pm 0.73$ & $2.17 \pm 0.73$ \\
Tensile modulus (MPa) & $1.35 \pm 0.32$ & $0.90 \pm 0.11$ & $0.41 \pm 0.37$ \\
Failure strain & $35.32 \pm 16.63$ & $31.91 \pm 13.91$ & $23.60 \pm 9.03$ \\
\hline
\end{tabular}

Fig. 1(a) shows that the micrographs of the untreated PAN fibers obtained by electrospinning have bead-free and homogenous morphology. The PAN fiber surfaces also seem featureless and smooth as shown in greater detail in the figure. The morphology of the PAN after the surface treatment with $\mathrm{Na}_{2} \mathrm{CO}_{3}$ shown in Fig. 1(c) has an uneven surface after treatment. As indicated by the arrows, the PAN fiber after $\mathrm{NaOH}$ as shown in Fig. 1(e) surface treatment reveals ripples and it is rougher compared with $\mathrm{Na}_{2} \mathrm{CO}_{3}$ surface treatment. The surface treatment processes were proved to give PAN fibers with different diameter range before the surface treatment (AFD (average fiber diameter): 2.06 \pm 0.54 ; MaxFD (maximum fiber diameter): 4.15 and MinFD (minimum fiber diameter):1.66). Next, the PAN fiber after the surface treatment with $\mathrm{Na}_{2} \mathrm{CO}_{3}$ becomes (AFD (average fiber 
diameter): $2.44 \pm 0.79$; MaxFD (maximum fiber diameter): 4.21 and MinFD (minimum fiber diameter):1.05) while the PAN fiber after the surface treatment with $\mathrm{NaOH}$ becomes AFD (average fiber diameter): $1.75 \pm 0.48$; MaxFD (maximum fiber diameter): 3.32 and MinFD (minimum fiber diameter):0.83). The measurements show that the electrospun PAN fiber diameter increases for $15 \%$ once the surface is treated with $\mathrm{Na}_{2} \mathrm{CO}_{3}$ while it decreases for $18 \%$ after being treated with $\mathrm{NaOH}$.

Fig. $1\left(\mathrm{~g}\right.$-h) shows that the PAN fiber after being treated by $\mathrm{Na}_{2} \mathrm{CO}_{3}$ and $\mathrm{NaOH}$ is fully coated with fibrin gel. The EDS results report the existence of fibrin with significant changes of nitrogen and oxygen element of the PAN fiber after the coating process. Increasing in the carbon composition confirms the existence of fibrin. The coating is fully covering the cellular fibers due to the structure of fibrinogen transformed into fibrin gel, deposited on the surface and forming a mesh of fibrils obviously in-between the junction fibers.

\subsection{Mechanical properties of untreated and treated PAN fiber}

Table 1 summarizes the tensile properties of the electrospun PAN fibers before and after reaction with $\mathrm{Na}_{2} \mathrm{CO}_{3}$ and $\mathrm{NaOH}$. It is noted that there are significant differences between the PAN fibers before and after the surface treatment with $\mathrm{Na}_{2} \mathrm{CO}_{3}$ and $\mathrm{NaOH}$ for tensile strength and tensile modulus. After the surface treatment, there were in total decreases in tensile strength, tensile modulus and strain to failure due to the loss of chain orientation. Tensile strength of the PAN before and after being treated with $\mathrm{Na}_{2} \mathrm{CO}_{3}$ and $\mathrm{NaOH}$ is $3.77 \mathrm{MPa}, 2.46 \mathrm{MPa}$ and $2.17 \mathrm{MPa}$. The decrease of tensile strength after $\mathrm{Na}_{2} \mathrm{CO}_{3}$ and $\mathrm{NaOH}$ surface treatment of the PAN fiber is as much as $34 \%$ and $42 \%$, respectively. Tensile modulus of the substrate decreases from $1.35 \mathrm{MPa}$ to $0.9 \mathrm{MPa}$ and $0.41 \mathrm{MPa}$ while strain decreases for $9 \%$ and $4 \%$ after being treated with $\mathrm{Na}_{2} \mathrm{CO}_{3}$ and $\mathrm{NaOH}$, respectively; while the value of the PAN fiber before and after being treated with $\mathrm{Na} 2 \mathrm{CO} 3$ and $\mathrm{NaOH}$ is $35 \%, 31 \%$ and $23 \%$. In theory, the tensile modulus decreases after the surface treatment because of the random PAN fiber would become gradually aligned during uniaxial tensile test. This also leads to decreasing PAN fiber diameter after the surface treatment, causing decrease in tensile strength; thus, the fiber will easily fracture.

\subsection{Surface characterization of untreated and treated PAN fiber}

Surface characterization of the treated and untreated PAN fiber is presented in Fig. 2. FTIR spectra of the PAN fibers, before and after treatment are included in Fig. 2(a). The control PAN molecule consists of functional groups such as methyl $\left(\mathrm{CH}_{3}\right)$ and nitrile $(\mathrm{C} \equiv \mathrm{N})$. It is found that the surface treatment in the presence of $\mathrm{Na}_{2} \mathrm{CO}_{3}$ and $\mathrm{NaOH}$ includes the stage of carboxyl, amide and aldehyde.

The PAN fiber shows a characteristic peak at 2260-2210 $\mathrm{cm}^{-1}$ before and after treatment with $\mathrm{NaOH}$ and $\mathrm{Na}_{2} \mathrm{CO}_{3}$ indicating the likely and expected presence of acrylonitrile due to nitrile stretch. The alkali reaction of $\mathrm{Na}_{2} \mathrm{CO}_{3}$ and $\mathrm{NaOH}$ will attack the chain of nitrile to become carboxyl group. The interface between these reactions involves amide formation, as can be seen in the spectra of $3400-3250 \mathrm{~cm}^{-1}$ for $1^{\circ}$ and $2^{\circ}$ amide and then proceeds through a carbonyl group which can be proven by conversion of $-\mathrm{CN}$ to $-\mathrm{COO}^{-}$groups. 

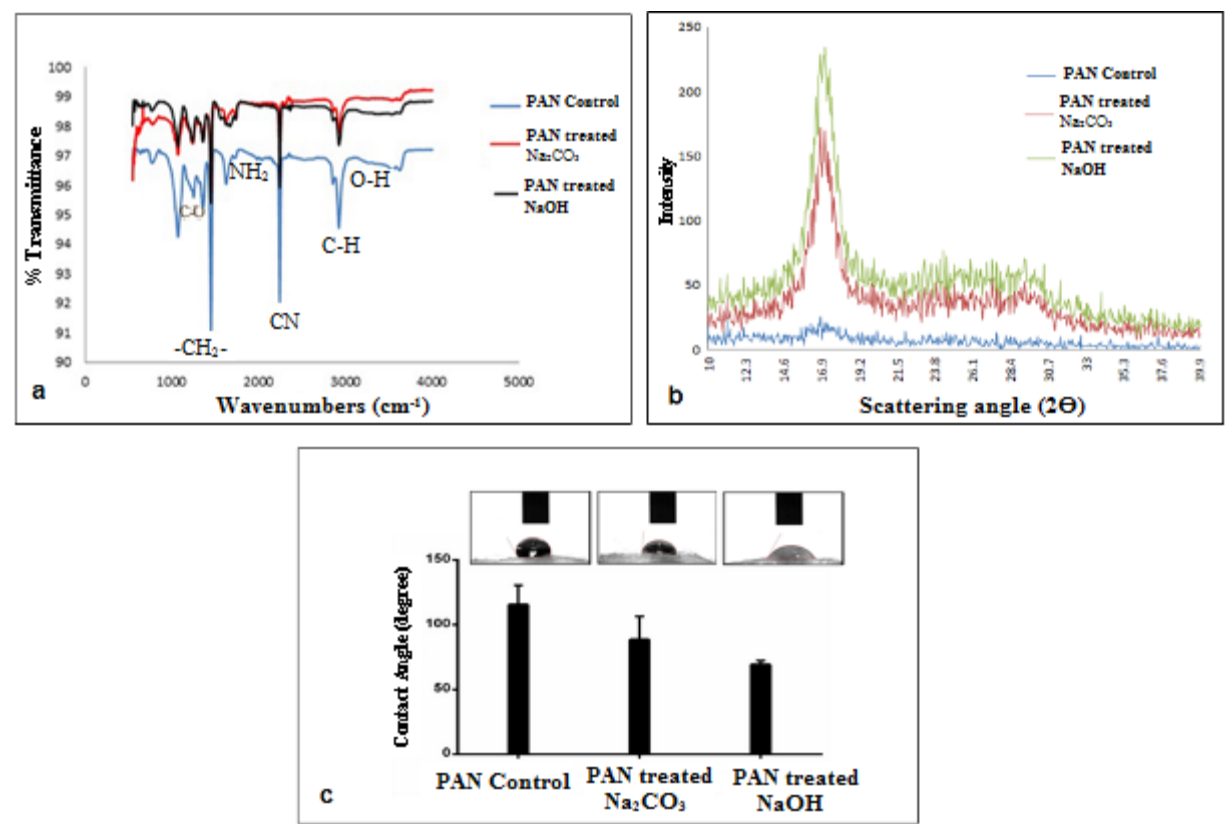

Fig. 2 (a) FTIR, (b) XRD, and (c) Contact angle results of PAN fiber, PAN treated with $\mathrm{Na}_{2} \mathrm{CO}_{3}$ and PAN treated with $\mathrm{NaOH}$

Briefly, the peak at $1645 \mathrm{~cm}^{-1}$ is assigned to carbonyl stretching, but the peak broadened after being treated into $1652 \mathrm{~cm}^{-1}$ for $\mathrm{NaOH}$ and $1649 \mathrm{~cm}^{-1}$ for $\mathrm{Na}_{2} \mathrm{CO}_{3}$ surface treatment. In conjunction with the peaks at $1320 \mathrm{~cm}^{-1}$ and $1000 \mathrm{~cm}^{-1}$ range (due in part to C-O stretch), $1760-1665 \mathrm{~cm}^{-1}$ (due to C-O-C bend), and broad absorption around $3300 \mathrm{~cm}^{-1}$ and $2500 \mathrm{~cm}^{-1}$ (due to -OH stretch) the carbonyl peak seems to confirm the presence of acrylate $(\mathrm{H} \mathrm{C}=\mathrm{C}(\mathrm{CH}) \mathrm{CO} \mathrm{R})$ as a co-monomer for $\mathrm{NaOH}$ surface treatment. This carboxylic acid formation will lead to the formation of secondary amines in which the hydroxyl group has been replaced by amine. However, in the presence of $\mathrm{Na}_{2} \mathrm{CO}_{3}$ surface treatment, it neither includes the stage of amide formation for second degree nor results in the complete exhaustion of nitrile groups in a PAN considering that $\mathrm{Na}_{2} \mathrm{CO}_{3}$ is not a very strong and reducing agent like $\mathrm{NaOH}$; hence it will neither fully attack nor harm the substrate.

The obtained XRD patterns are shown in Fig. 2(b). A number of crystalline peaks are observed for pure PAN, which can be attributed to the semi- crystalline structure of this polymer. The polymer exhibits a diffraction peak at $16.9^{\circ}$, which is the typical peak for a polyacrylonitrile polymer. Two equatorial peaks are shown with one at $2 \theta=29.5 \AA$ corresponding to a spacing of $\mathrm{d} \approx 3.03 \AA$ from the $\left(\begin{array}{lll}1 & 1 & 0\end{array}\right)$ reflection and the other at $2 \theta=17.0 \AA$ corresponding to a spacing of $d \approx 5.3 \AA$ from the $\left(\begin{array}{lll}1 & 0 & 0\end{array}\right)$ reflection. These peaks are common to the fiber diffraction pattern of PAN with hexagonal crystal system [21]. The weak peak of the PAN control is shown from the diffraction pattern with the value of $2 \theta$ at $17.0^{\circ}$. This proves that the fibers fabricated using electrospinning give limited crystallinity. This low crystallinity leads to stretched PAN chains solidified rapidly after elongation, preventing crystal formation in the electrospun PAN fibers. 
In contrast, the PAN with $\mathrm{Na}_{2} \mathrm{CO}_{3}$ and $\mathrm{NaOH}$ surface treatment as increased in crystallinity even after a short-timing treatment shows two diffraction peaks indexed with values of $2 \theta$ of $17.0^{\circ}$ and $29.5^{\circ}$. The crystallinities of the $\mathrm{NaOH}$-treated fiber are higher than the PAN control and the PAN after being treated with $\mathrm{Na}_{2} \mathrm{CO}_{3}$. The main factor depends on the alkali concentrations selected for the treatment and the type of fiber studied [22]. The crystallinity factor will lead to the structural changes of the PAN fibers after surface treatments; thus, it will influence the course of their entire degradation process.

The contact angle of the PAN-modified surfaces treated via $\mathrm{Na}_{2} \mathrm{CO}_{3}$ and $\mathrm{NaOH}$ as well as the control are shown in Figure 2(c). It indicates that the PANs treated by $\mathrm{Na}_{2} \mathrm{CO}_{3}$ and $\mathrm{NaOH}$ are more hydrophilic (a significant lower contact angle) than found in an untreated PAN. The contact angle of the PAN surface of the PAN is reduced from $115^{\circ}$ to $88^{\circ}$ and $64^{\circ}$ after being treated with $\mathrm{Na}_{2} \mathrm{CO}_{3}$ and $\mathrm{NaOH}$, respectively. These results clearly indicate that the untreated PAN fibers have the least attraction toward deionized water. However, this is improved upon by the surface treatment. The water contact angle of the PAN surface gradually decreases after being treated with $\mathrm{Na}_{2} \mathrm{CO}_{3}$ and $\mathrm{NaOH}$. It is noteworthy that the receding contact angle decreases for all the PAN fibers after the surface treatment.

\subsection{Endothelial cell adhesion and proliferation}

Once HUVECs are seeded onto both untreated and surface-treated and coated PAN fibrous scaffolds in presence of fibrin, the cell attachment is evaluated at day 1 and day 3 and presented in Fig. 3. After day 1, HUVECs cultured on PAN fibers are rounded in phenotype for all fibers (Fig. $3(\mathrm{a}, \mathrm{d}, \mathrm{g})$ ). This is due to the short timing of culture. HUVECs seem to be securely attached and spread on the surface in a flatten formation, regardless of the surface treatments and surface coating after day 3 . It is evident that the cells are more actively spreading across the modified surfaces (Fig. 3 (e) and (h)) while the cells remain separately on PAN control even for day 3. This suggests that the HUVECs adhered to PAN treated with $\mathrm{Na}_{2} \mathrm{CO}_{3}$ and $\mathrm{NaOH}$ and then coated with fibrin surface are higher than those found on the PAN control at the time points of 1 and 3 days. This is proven by staining after day 3 culture (Fig. 3 (f,i)) which confirms that not only the confluent HUVECs layer is formed, but also that the cells are oriented completely along the aligned fiber direction and that they exhibit an elongated morphology for both surface treated fibers coated with fibrin.

The metabolic behavior and cell proliferation are characterized by MTT Assay. Fig. 3(i) depicts the proliferation of HUVECs on the treated PAN fiber scaffold in comparison with that on the gold standard, tissue culture treated polystyrene (TCPS) and the PAN untreated. Absorbance of the PAN treated with $\mathrm{Na}_{2} \mathrm{CO}_{3}$ and $\mathrm{NaOH}$ coated with fibrin increases by increasing time as shown in Fig. 3(i). However, the PAN control increases absorbance slowly because of the reduced toxic of fluorine coming from DMF which is a PAN solution during fabrication of fibers. The MTT absorbance of PAN after being treated with $\mathrm{Na}_{2} \mathrm{CO}_{3}$-fibrin coated shows increases throughout the testing period while the PAN treated with $\mathrm{NaOH}$-fibrin coated slowly increases from day 5 to day 7 with absorbance value $0.38 \pm 0.03$ and $0.39 \pm 0.02$, respectively. The PAN treated with $\mathrm{NaOH}$ fibrin coated preceding the PAN treated with $\mathrm{Na}_{2} \mathrm{CO}_{3}$-fibrin coated shows as much as $4 \%$ on day 3 while for day 5 and day 7 absorbance shows $0.37 \pm 0.02$ and $0.38 \pm 0.02$, respectively, for the PAN treated with $\mathrm{Na}_{2} \mathrm{CO}_{3}$. 

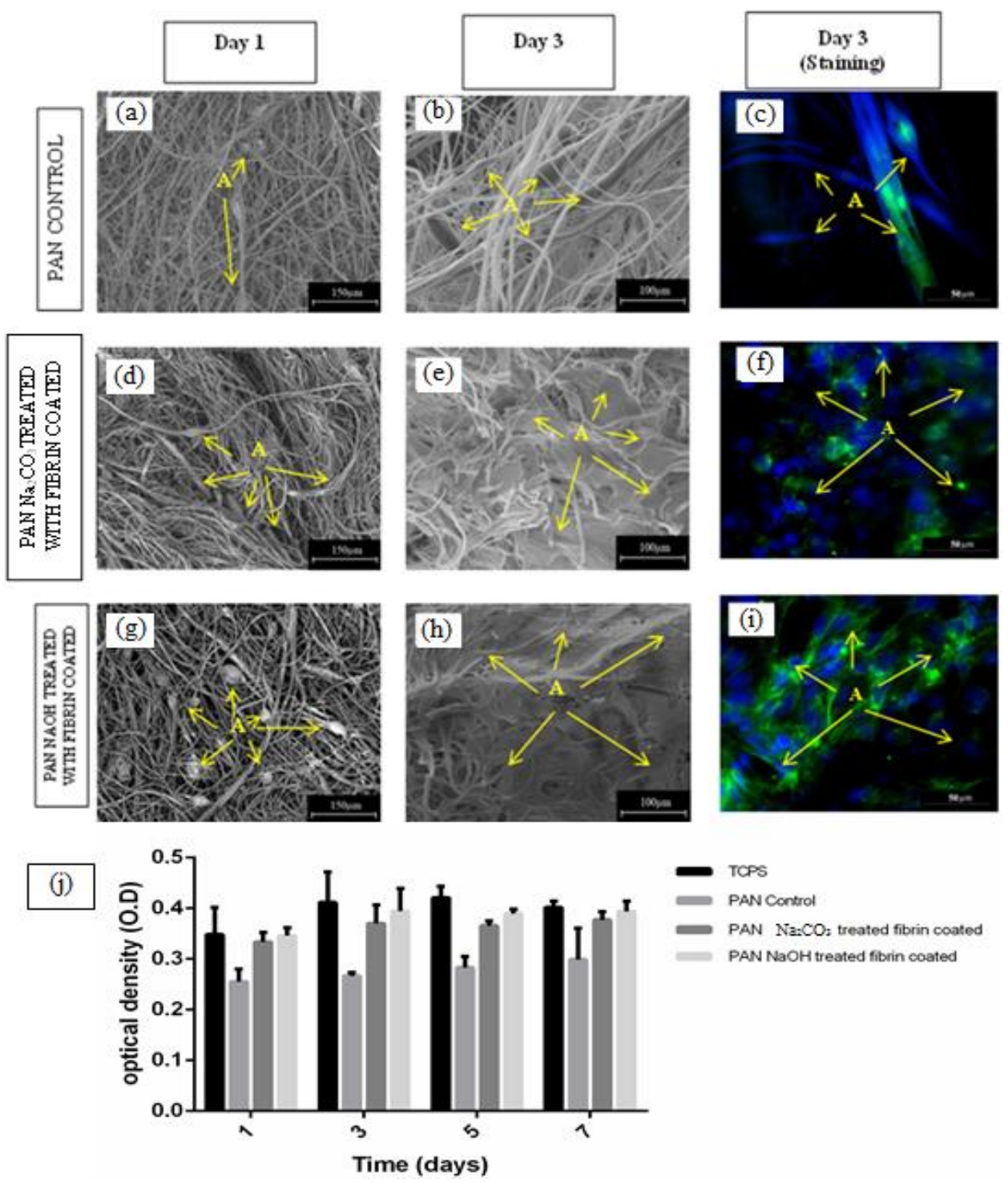

Fig. 3 SEM and images of HUVECs cultured on an untreated fiber as control (a,b,c); $\mathrm{Na}_{2} \mathrm{CO}_{3}$ treated and fibrin coated $(\mathrm{d}, \mathrm{e}, \mathrm{f}) ;$ and $\mathrm{NaOH}$ treated and fibrin coated $(\mathrm{g}, \mathrm{h}, \mathrm{i})$ after 1 and 3 days of study. Letters "A" indicate HUVEC cells. MTT test on cytotoxicity of PAN before and after surface treated to HUVECs also presented (i). "TCPS" indicate tissue culture treated polystyrene 


\section{DISCUSSIONS}

The PAN fiber has been used for membrane applications [7]. In this study, the PAN fiber is prepared to promote endothelial cell adhesion and proliferation. The surface treatment and bioactive coating of polymer fiber may lead to endothelial cell proliferation thus encouraging endothelial network or endothelialization, as presented elsewhere [23]. The objective of the study is to examine the effect of bioactive coating on the PAN fiber to the HUVEC responses, which complements the previous study by Groth et al. that used the PAN fiber for fibroblast cell for wound healing application [5].

It has been previously shown that the use of $\mathrm{Na}_{2} \mathrm{CO}_{3}$ and $\mathrm{NaOH}$ removes the natural surface wax thereby exposing the underlying texture of substrates [24]. This improves the wetting and wicking properties of the material which in turn increases the material surfaces for better surfacing coating [25]. In this experiment, it is observed that the PAN fiber shows increased hydrophilicity after being treated with $\mathrm{Na}_{2} \mathrm{CO}_{3}$ and $\mathrm{NaOH}$ thus improving coating of fibrin gel on PAN fibers. The bioactive protein, in this case fibrin, has become a positive surface charged at neutral $\mathrm{pH}$; this will attract negative charge on the treated PAN sample [19]. The fibrin coating is able to attract HUVECs on the PAN fiber since fibrin has directs cellular responses through specific receptor [26].

Many studies have already discussed $\mathrm{NaOH}$ surface treatment on various substrates [14, 24]. Afra et al. showed porous surface and rough morphology on PET substrate after surface treatment of 2 hours with $\mathrm{NaOH}$ [13]. A higher concentration of $\mathrm{NaOH}$ and longer period of surface treatment will cause degradation of surface fiber [19] or grooved serrated surfaces. It has been reported that the substrate with very high surface roughness decreases cell adhesion onto its surface [27]. Therefore, in this study the lower concentration for both treatments are used. There are no significant differences in morphology on the PAN surface after being treated with both $\mathrm{NaOH}$ and $\mathrm{Na}_{2} \mathrm{CO}_{3}$ since the concentration for both treatments is as low as 0.1 and 0.2 molar of $\mathrm{Na}_{2} \mathrm{CO}_{3}$ and $\mathrm{NaOH}$, respectively.

Even though the morphology of the PAN fiber after the surface treatment does not give much difference, the diameter of fibers is affected. This is due to the transformation of nitrile to carboxylic group of the PAN surface which may result in a decrease of fiber diameter. However, incomplete exhaustion of nitrile group for $\mathrm{Na}_{2} \mathrm{CO}_{3}$ surface treatment gives an advantage to $\mathrm{Na}_{2} \mathrm{CO}_{3}$ compared to $\mathrm{NaOH}$ surface treatment in terms of mechanical properties since the fiber diameter is strongly related to strength of the fiber [28]. Tensile strength of the PAN fiber after $\mathrm{Na}_{2} \mathrm{CO}_{3}$ treatment is higher than $\mathrm{NaOH}$ surface treatment but still lower than PAN before the surface treatment. This is because the fiber's exposure to the heated surface treatment makes the fiber give an emission and auto exhaustion to the environment [29].

Alteration in physical characteristics of fibers will influence tensile properties due to increasing shrinkage and density of fibers [14]. The decreasing result for tensile modulus of PAN after treatment with $\mathrm{Na}_{2} \mathrm{CO}_{3}$ and $\mathrm{NaOH}$ shows that the PAN surface is relatively ductile due to exhaustions of nitrile group. This has also led to the changes of crystallinity because acrylonitrile is a reactive chemical that polymerizes spontaneously when heated in the presence of a strong alkali. Result of mechanical properties depends on the material used. Instead of synthetic fiber, previous study used natural fiber for base material [29]. Alteration in ductility of specific material after removal of impurities has modified mechanical result [28]. However, tensile strength in this experiment before and after the surface treatment is still in the range of coronary artery which is from $1.40 \mathrm{MPa}$ to $11.14 \mathrm{MPa}$ [23]. 
Cytotoxicity test on PAN fibers after the surface treatment with $\mathrm{Na}_{2} \mathrm{CO}_{3}$ and $\mathrm{NaOH}$ shows these fibers are suitable for growth of HUVECs, attaining increasing in cell viability until day 7 of culture. These observations suggest that the fibrin assisted increases proliferation of HUVECs and allows the proliferation of the cells into the interior of the PAN fiber and the uniform distribution of fibrin coated on PAN fiber after the surface treatment with $\mathrm{Na}_{2} \mathrm{CO}_{3}$ and $\mathrm{NaOH}$ has enhanced proliferation of infiltrated cells throughout the fiber volume. The SEM micrographs of HUVECs on PAN control and PAN treated with $\mathrm{Na}_{2} \mathrm{CO}_{3}$ - fibrin coated and $\mathrm{NaOH}$ scaffolds obtained on day 1 of culture show a normal morphology of cell growth on the fibers. HUVEC cells disconnects to individual cells, round phenotype for all fibers. This is due to the shortened time of culture. This cell behavior is the same as in the previous report [8], where fibers have low surface density and large inter fiber which does not encourage adhesion of the cells across the nearest fibers in short time seeding. HUVECs attach and spread more on PAN substrate after surface treatments than PAN control by day 3. Also, HUVECs are numerous and well-spread, forming monolayer cell on the PAN treated with $\mathrm{NaOH}$ scaffolds while reaching sub confluence. Some cells aggregate along the fibers on PAN treated with $\mathrm{Na}_{2} \mathrm{CO}_{3}$ as confirmed by double-staining with Alexa Fluor 488 for the cell cytoskeleton (i.e., acting filaments) and with Hoechst 33258 for nuclei.

These observations point to the significance of the HUVECs adhesion increase due to better hydrophilicity caused by the PAN fiber surface treatment process subsequently coated with fibrin. It also shows that fibrin was immobilized on the PAN, which is important for strong cell adhesion [30]. Fibrin contains many integration-binding sites and this reason makes it easier for cells to adhere to coated PAN fiber [31]. Formation of focal adhesions only occurs if the ligands can withstand cell contractile forces as acting stresses fibers while focal adhesions are critical for cell survival. This indicates that culturing cells on native substrates proves that cell attachment, spreading and growth enhanced, depends on the substrate, which has been reported elsewhere [32]. SEM and staining micrographic observations support the trend of HUVECs proliferation quantified by the MTT assays.

\section{CONCLUSIONS}

This study has attempted to attach HUVECs on PAN via two different surface treatments with $\mathrm{Na}_{2} \mathrm{CO}_{3}$ and $\mathrm{NaOH}$, then coated with fibrin gel. The attachment of HUVECs on PAN after $\mathrm{Na}_{2} \mathrm{CO}_{3}$ surface treatment can be another option for wet chemical treatment rather than common $\mathrm{NaOH}$ since $\mathrm{Na}_{2} \mathrm{CO}_{3}$ surface treatment gives improvement in wettability and mechanical properties. The presence of carboxyl functions on PAN fiber after surface treatment can be an advantage since fibrin can be covalently coupled via a simple wet chemistry. The fibrin-coated PAN after the surface treatment enhanced endothelialization, as observed in spreading cell morphology and increasing cell proliferation. This is another successful finding of the PAN fiber on cells after another research which has proved it for fibroblast cells.

Acknowledgements: I. Sukmana is supported by Universitas Lampung and Kemenristekdikti Indonesia grants. The rest of the authors are supported by the Malaysian Ministry of Higher Education (MOHE) (vote\# 4F124) and Tier-1 Research grant by Universiti Teknologi Malaysia (vote \# 03H12). 


\section{REFERENCES}

1. Houa, D., Huanga, X., Weia, A., 2011, Surface modification of electrospun PAN nanofibers and its application for adsorption of lead ions, Journal of Fiber Bioengineering \& Informatics, 4, pp.383-388.

2. Panapoy, M., Dankeaw, A., Ksapabutr, B., 2008, Electrical conductivity of PAN-based carbon nanofibers prepared by electrospinning method, Thammasat Int J Sc Tech, 13, pp. 11-17.

3. Yu, X., Xiang, H., Long, Y., Zhao, N., Zhang, X., Xu, J., 2010, Preparation of porous polyacrylonitrile fibers by electrospinning a ternary system of PAN/DMF/H $2 O$, Materials Letters, 64, pp. 2407-2409.

4. Farsani, R.E., Raissi, S., Shokuhfar, A., Sedghi, A., 2009, FT-IR study of stabilized PAN fibers for fabrication of carbon fibers, World Academy of Science, Engineering and Technology, 50, pp. 430-433.

5. Groth, T., Seifert, B., Malsch, G., Albrecht, W., Paul, D., Kostadinova, A., Krasteva, N., and Altankov, G., 2002, Interaction of human skin fibroblasts with moderate wettable polyacrylonitrile-copolymer membranes, Journal of biomedical materials research, 61, pp. 290-300.

6. Wang, Z.-G., Wan, L.-S., Xu, Z.-K., 2007, Surface engineerings of polyacrylonitrile-based asymmetric membranes towards biomedical applications: An overview, Journal of Membrane Science, 304, pp. 8-23.

7. Kang, Y., Ahn, K., Jeong, S., Bae, J., Jin, J., Kim, H., H.G., Hong, S.W., and Cho, C.R., 2011, Effect of plasma treatment on surface chemical-bonding states and electrical properties of polyacrylonitrile nanofibers, Thin Solid Films, 519, pp. 7090-7094.

8. Shi, Q., Vitchuli, N., Nowak, J., Caldwell, JM., Breidt, F., Bourham, M., M., Zhang, X., and McCord, M., 2011, Durable antibacterial Ag/polyacrylonitrile (Ag/PAN) hybrid nanofibers prepared by atmospheric plasma treatment and electrospinning, European Polymer Journal, 47, pp. 1402-1409.

9. Fleming, R., Pardini, L., Brito, Jr, C., Oliveira, Jr, M., Alves, N., Massi, M., 2011, Plasma treatment of polyacrylonitrile/vinyl acetate films obtained by the extrusion process, Polymer Bulletin, 66, pp. 277-88.

10. Zhao, Z.-P., Li, J., Wang, D., Chen, C.-X., 2005, Nanofiltration membrane prepared from polyacrylonitrile ultrafiltration membrane by low-temperature plasma: 4. grafting of $N$-vinylpyrrolidone in aqueous solution, Desalination, 184, pp. 37-44.

11. Zhao, Z.-P., Li, J., Zhang, D.-X., Chen, C.-X., 2004, Nanofiltration membrane prepared from polyacrylonitrile ultrafiltration membrane by low-temperature plasma: I. Graft of acrylic acid in gas, Journal of Membrane Science, 232, pp. 1-8.

12. Ulbricht, M., Oechel, A., Lehmann, C., Tomaschewski, G., Hicke, H.G., 1995, Gas-phase photoinduced graft polymerization of acrylic acid onto polyacrylonitrile ultrafiltration membranes, Journal of applied polymer science, 55, pp. 1707-23.

13. Hadjizadeh, A., Ajji, A., Bureau, M.N., 2010, Preparation and characterization of NaOH treated micro-fibrous polyethylene terephthalate nonwovens for biomedical application, Journal of the mechanical behavior of biomedical materials, 3, pp. 574-83.

14. Liu, W., Cai, M., He, Y., Wang, S., Zheng, J., Xu, X., 2015, Development of antibacterial polyacrylonitrile membrane modified with a covalently immobilized lysozyme, RSC Advances, 5, pp. 84432-84438.

15. Dyatlov, V.A., Grebeneva, T.A., Rustamov, I.R., Koledenkov, A.A., Kolotilova, N.V., Kireev, V.V., and Prudskov, B.M., 2012, Hydrolysis of polyacrylonitrile in aqueous solution of sodium carbonate, Polymer Science Series B, 54, pp. 161-166.

16. Sukmana, I., Djuansjah, J.R.P., 2013, Sandwiched polymer fibre in fibrin matrices for the dictation of endothelial cells undergoing angiogenesis, Journal of Physics: Conference Series, 423(012049), pp. 1-4.

17. Herrick, S., Blanc-Brude O., Gray A., Laurent, G., 1993, Fibrinogen, the International Journal of Biochemistry \& Cell Biology, 31, pp. 741-746.

18. Wang, J., Yue, Z., Ince, J.S., Economy, J., 2006, Preparation of nanofiltration membranes from polyacrylonitrile ultrafiltration membranes, Journal of Membrane Science, 286, pp. 333-341.

19. Chiu, H., Lin, J., Cheng, T., Chou, S., 2011, Fabrication of electrospun polyacrylonitrile ion-exchange membranes for application in lysozyme, Express Polymer Letters, 5, pp. 308-317.

20. Hou, X., Yang, X., Zhang, L., Waclawik, E., Wu, S., 2010, Stretching-induced crystallinity and orientation to improve the mechanical properties of electrospun PAN nanocomposites, Materials \& Design, 31, pp. 1726-1730.

21. Hou, C., Qun, W., Qu, R., Wang, C., 2006, Interaction between polyacrylonitrile and alkalis, Journal of applied polymer science, 102, pp. 272-275.

22. He, W., Ma, Z., Yong, T., Teo, W.E., Ramakrishna, S., 2005, Fabrication of collagen-coated biodegradable polymer nanofiber mesh and its potential for endothelial cells growth, Biomaterials, 26, pp. 7606-7615. 
23. Nilghaz, A., Wicaksono, D.H., Gustiono, D., Majid, F.A.A., Supriyanto, E., Kadir, M.R.A., 2012, Flexible microfluidic cloth-based analytical devices using a low-cost wax patterning technique, Lab on a Chip, 12, pp. 209-218.

24. Basu, S., Yang, S-T., 2005, Astrocyte growth and glial cell line-derived neurotrophic factor secretion in three-dimensional polyethylene terephthalate fibrous matrices, Tissue engineering, 11, pp. 940-952.

25. Xu, C., Yang, F., Wang, S., Ramakrishna, S., 2004, In vitro study of human vascular endothelial cell function on materials with various surface roughness, Journal of biomedical materials research Part A, 71, pp. 154-161.

26. Liu, C-K., Sun, R-J., Lai, K., Sun, C-Q., Wang, Y-W., 2008, Preparation of short submicron-fiber yarn by an annular collector through electrospinning, Materials Letters, 62, pp. 4467-4469.

27. Van, de, Weyenberg, I., Chi Truong, T., Vangrimde, B., Verpoest, I., 2006, Improving the properties of UD flax fibre reinforced composites by applying an alkaline fibre treatment, Composites Part A: Applied Science and Manufacturing, 37, pp. 1368-1376.

28. Keun, Kwon, I., Kidoaki, S., Matsuda, T., 2005, Electrospun nano- to microfiber fabrics made of biodegradable copolyesters: structural characteristics, mechanical properties and cell adhesion potential, Biomaterials, 26, pp.3929-3939.

29. Adamczak, M., Scislowska-Czarnecka, A., Genet, M.J., Dupont-Gillain, C.C, Pamula, E., 2011, Surface characterization, collagen adsorption and cell behaviour on poly (L-lactide-co-glycolide), Acta of Bioengineering \& Biomechanic, 13(3), pp. 63-75.

30. Mwaikambo, L.Y., Ansell, M.P., 2002, Chemical modification of hemp, sisal, jute, and kapok fibers by alkalization, Journal of applied polymer science, 84, pp. 2222-2234.

31. Hadjizadeh, A., Doillon, C.J., Vermette, P., 2007, Bioactive polymer fibers to direct endothelial cell growth in a three-dimensional environment, Biomacromolecules, 8, pp. 864-873.

32. Sukmana, I., Kadir, M.R.A., Djuansjah, J.R.P., 2013, In vitro angiogenesis assay for the guidance of microvessel containing multi-cellular lumen formation, Advanced Science Letters, 19, pp. 3547-3550. 